\title{
DIAGNOSTIC AND MANAGEMENT SYSTEM SPECIFIED FOR CONTROL OF ENGINE EQUIPPED WITH THE HCCI COMBUSTION TECHNOLOGY
}

\author{
Michal PUŠKÁR, Melichar KOPAS, Dušan PUŠKÁR
}

Faculty of Mechanical Engineering, Technical University of Košice, Letná 9, 04200 Košice, Slovakia e-mail address: michal.puskar@ tuke.sk, melichar.kopas@tuke.sk, dusan.puskar@tuke.sk

\begin{abstract}
On the present there is very intensively emphasized the environmental protection, which is also connected with reduction of emissions produced by the vehicles. The actual European emission standard EURO 6 will be replaced very soon with the new and even stricter standard EURO 7. There is a well-known fact that the new regulations are demanding with regard to the NOX emissions. However, there is at disposal a suitable technical solution, namely in the form of an innovative engine technology, which is called the HCCI. A principle of this technology consists in a self-ignition of the homogenous air-fuel mixture using the compression process. Combustion of the mixture is performed in the whole compression volume without a spark ignition, whereby the NOX emission level is almost negligible. However, this technology is also characterised by several serious problems, for example there is occurring a complication concerning control of the self-ignition phenomenon. The presented article introduces an original diagnostic system, which enables to control the whole self-ignition system and in this way to ensure a reliable operation of the HCCI engine. This system is patented now as well as it was tested in an experimental vehicle built for the international competition "shell eco marathon".
\end{abstract}

Keywords: diagnostic system, management, control, HCCI technology

\section{INTRODUCTION}

The automotive industry is permanently facing to the durable challenges that are presented in the form of requirements concerning efficient exploitation of the fuel energy, reduction of the emissions and application of the new technologies. Nowadays there is valid within the European countries the emission standard Euro 6, which should help to eliminate most of the harmful substances that are occurring in the air. The upcoming new emission standard Euro 7 will be even more strict and demanding $[1,2]$.

In the 2015 year occurred information about a fact that in some of the motorcars was installed a software, which enabled to hide the over-limit values of the nitrogen oxides during the emission testing process. This affair is called "dieselgate". Officially, all the motorcars fulfil limits defined for production of the nitrogen oxides $\left(\mathrm{NO}_{\mathrm{X}}\right)$. The emission testing process is performed in the laboratory conditions and the above-mentioned "special" software was able to overreach the testing machine. The collusive software cooperated with the engine control unit, identified the measuring process and switched the engine into the operational regime with the reduced emission values $[3,4]$. It is possible to say that the current emission limits are very demanding.

From this reason there are occurring serious problems for the automobile factories how to meet the emission standards [4]. Technological development of the future and better engines, together with application of the anti-emission actions, requires expensive investments.

However, there is at disposal one possible solution, which consists in application of a new, special technology. This innovative technology is called the "Homogeneous Charge Compression Ignition", i.e. the HCCI technology, which is based on a specific combination of the gasoline engine (using the spark ignition principle) with the diesel engine (utilizing the compression ignition process). Such combination of two quite different ignition methods in one combustion engine offers the best operational characteristics of both ignition systems. There is applied in this case a gasoline as the engine fuel, but the indicated efficiency of such engine is higher, similarly to the diesel engine [5-10].

The engine indicated efficiency is a function of the compression ratio and specific heats ratio, Fig.1.

The process of the homogenous charge combustion is running at once within the piston combustion volume. Thanks to this fact the whole charge is combusted almost completely. Efficiency level of the gasoline exploitation is very high thanks to application of the progressive and perspective HCCI technology. Another positive result consists in a substantial reduction of the engine fuel consumption, together with reduction of the exhaust gas emissions and what is important the $\mathrm{NO}_{\mathrm{X}}$ emission level is almost zero. On the other 
hand, it is necessary to say that application of the HCCI technology induces some of fundamental problems, for instance a high level of the pressure values, high thermal loading during the compression process, complicated control of the self-ignition process etc. [11].

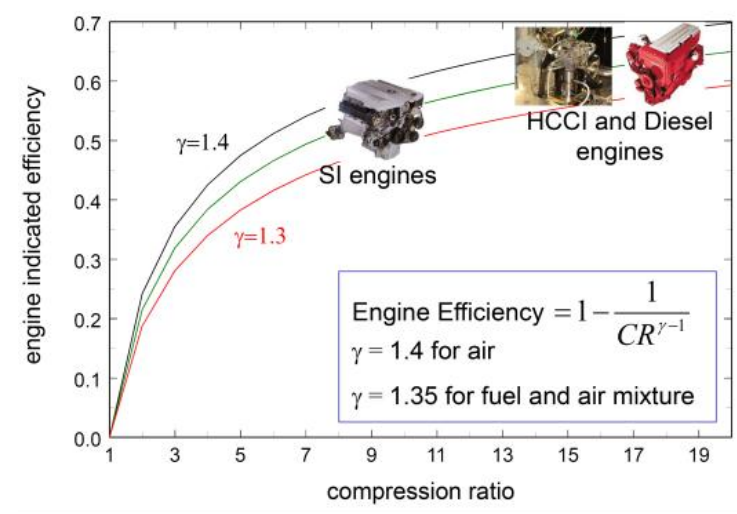

Fig. 1. Indicated efficiency of various engine types

The worldwide reputable automotive companies are dealing with a development of the HCCI technologies. The contemporary problems concerning the diesel engines emphasize an importance of such development strategy, which is based on the HCCI-engines. The innovative HCCI technology, which is integrated together with the modern motor-management components (e.g. with the direct fuel injection, VVT etc), enables to save the fuel and to fulfil the future emission standards $[12,13]$. The global efficiency of the piston combustion engine, which is equipped with the HCCI technology, is close to the diesel engine efficiency, however the HCCI-engine does not require application of an expensive system necessary for elimination of the NOx emissions. Effectiveness of the HCCI system is based on the fuel combustion at lower temperature levels and on reduction of heat losses, together with the decreased CO2 emissions [14-16].

The piston combustion engine equipped with the HCCI technology is determined not only as a driving aggregate for the "classic" motorcars, but this kind of engine can be also used as a driving unit of the electric generators installed in the vehicles with the hybrid drives [16].

\section{EXPERIMENTAL MODEL AND OPERATIONAL CONDITIONS}

A physical and technical principle of the HCCIengine operation, which is using combustion of the gasoline-air mixture, is well known among the engine designers already during a longer time. This technology offers a possibility to increase the gasoline engine efficiency so that it could be similar to the diesel engine efficiency. The self-ignition process is running at once in the combustion area. The gasoline-air fuel mixture is ignited as a result of the self-ignition process after compression of the charge. In any case, application of the spark plugs remains still necessary, for example in the case of the cold engine start or during a high-load working regime of the engine. If the engine is operating with a low-level loading, so there is activated the controlled homogenous charge compression ignition process. The specific fuel consumption of the combustion engine equipped with the HCCI technology is similar to the specific fuel consumption of the diesel engine, however it is not necessary in this case to apply an expensive system intended for elimination of the $\mathrm{NO}_{\mathrm{X}}$ emissions [16].

The main problem, which is connected with a real application of the HCCI technology, consists in a fact that controlling of the fuel mixture selfignition process is difficult. The most relevant problem occurs if the engine temperature conditions are variable, because in such a case the HCCI regime is unstable and there is arising in this way a dangerous possibility of engine construction damage. The main task of this article is such conversion or transformation of the standard gasoline engine in order it will be able to operate in the stable regime of HCCI. The experimental engine is a single-cylinder, 4-stroke gasoline engine with the fuel direct injection and with the compression ratio increased up to the value 19:1. The applied fuel injection system is a product of the company Ecotrons. The electronically controlled throttle valve allows regulation of the engine speed using throttling of the air intake [12-16].

There was developed a new heat control system, which is arranged according to Fig. 2, in order to perform the above-mentioned conversion of the common gasoline engine so that it can work in the HCCI regime. This system enables to control temperature of the gases, which are entering the cylinder and in this way the given system also controls the self-ignition process. The input air is flowing through the throttle valve. The fuel is injected into the intake air and the fuel-air mixture is passing through the compressor. The compressed fuel mixture is divided into two individual flows: the first one is the "hot flow" and the second is the "cold flow". The hot flow is passing through the heat exchanger and it is warmed-up by the exhaust gases. The cold flow is streaming through the cooler. The both flows (the hot flow and the cold flow) are independent, i.e. they are flowing individually. The engine cylinder is equipped with a mixing valve, which mixes both flows and in this way it regulates the temperature during the suction process. A computer, using the electric servomotor, controls the regulation valve.

The feedback signal is obtained from measuring of the cylinder pressure every 0.5 crank angle degree (CAD). Analysis of the cylinder pressure, which is performed during measuring of the released heat, determines the combustion timing. 


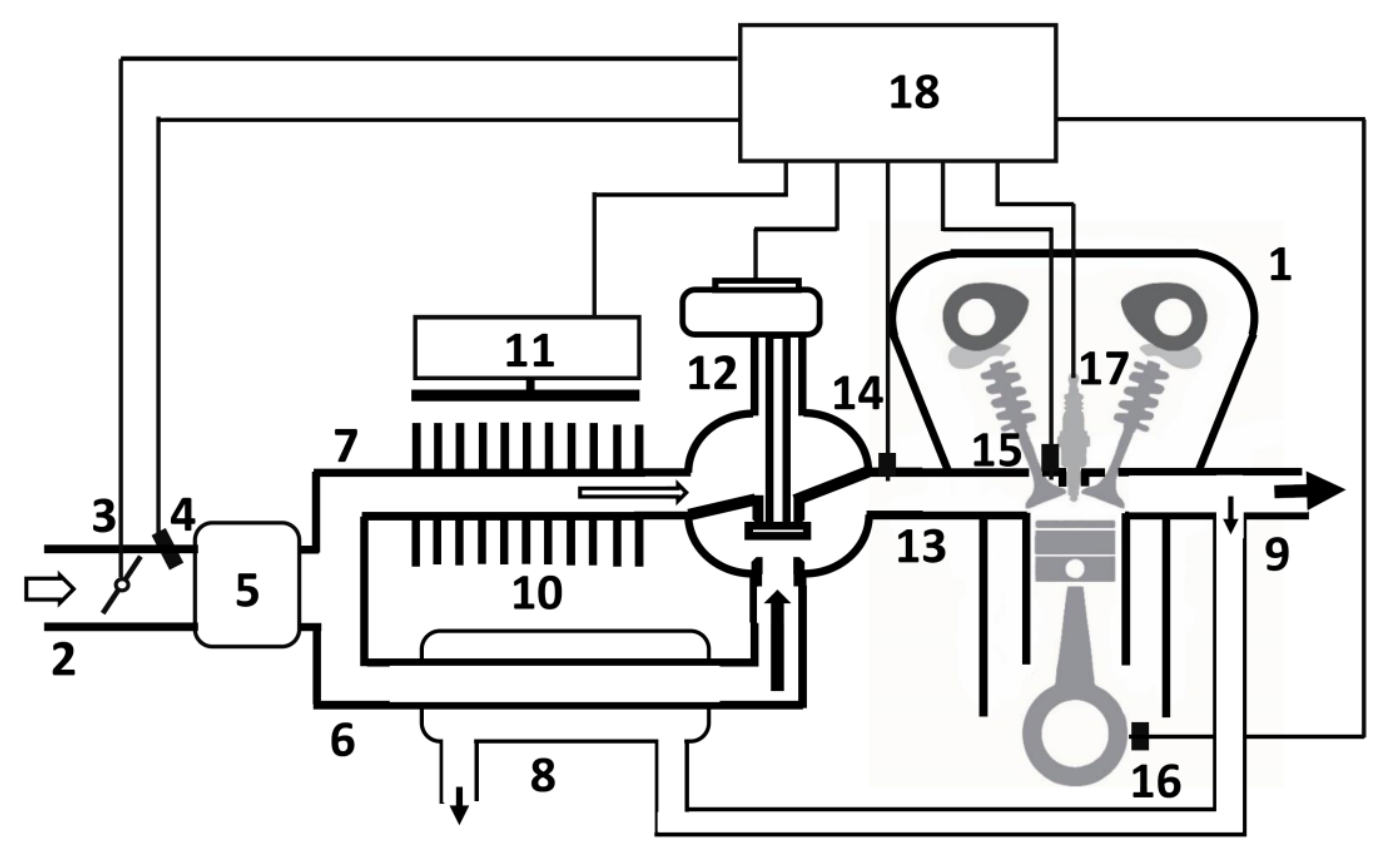

Fig. 2. System based on thermal control of the homogenous fuel mixture self-ignition process with compression ( $1-$ combustion engine, 2 - suction pipe, 3 - throttle valve, 4 - fuel injector, 5 - compressor, 6 - heated pipe, 7 - cooled pipe, 8 heater, 9 - exhaust gas pipe, 10 - cooler, 11 - fan, 12 - mixing valve, 13 - output pipe, 14 - air temperature sensor, 15 -

cylinder pressure sensor, 16 - crankshaft speed sensor, 17 - spark ignition, 18 - computer with s ECU)

The combustion timing is defined as such crank angle, by which there is released $50 \%$ of the heat (CA50). The calculated combustion timing is applied as the feedback, which enables to realize control of the combustion process by means of the above-mentioned temperature regulation valve. The installed motor-management software is processing all the sensed data as well as it is managing the whole engine operational system.

\section{RESULTS AND DISCUSSION}

A specific time moment of ignition with the minimal fuel consumption can be defined for the given operational point, which is characterised by the values of engine speed and engine torque. However, this optimal timing is always a compromise among the effective engine work obtained from combustion of the fuel mixture, the heat transfer losses and the combustion process efficiency. If the process of fuel mixture combustion is starting before the top dead centre (TDC) position of the engine piston, thus expansion of hot gases, as well as the reduced cylinder volume, rapidly increases the cylinder pressure and temperature. In this way there is braked the piston movement. Moreover, increasing of the temperature values causes a raising amount of the NOemissions, whereby a too-high in-cylinder pressure is able to damage the engine, as well.

Furthermore, if the pre-ignition value is rising, there is also at disposal a longer time interval for heat transfer. Additionally, if the ignition moment is closer to the TDC, the in-cylinder pressure and the cylinder temperature are reduced and from this reason the active or positive work of the expanding gas is lower. There is defined an optimal combustion timing for every engine operational point as a compromise among all the abovementioned influences. Prediction of the optimal combustion timing is a complicated task because it is necessary to take into consideration various contradictory processes and therefore it must be determined experimentally. A possible solution of this task is application of the extreme-seeking control (ES), which can be used as a helpful tool in order to make this process easier. The ES is a very useful procedure, which is determined for selecting of the unknown and required values in order to optimise the non-linear performance indicator. There is used within this article just the fuel consumption as the performance indicator and the ES serves for determination of the required combustion timing, which minimises this indicator. The ES is utilized for minimisation of the HCCI engine fuel consumption by tuning of the combustion timing value according to Fig. 3 . The combustion timing value is the output value, which is very sensitive to the intake temperature. There is applied in this case the discrete ES version determined for minimisation of the cost function, which is able to quantify performance of the controller. The costs depend on differences between the actual and the required combustion timing. The controller parameters are actualised in the online regime using the optimisation process. There is an important and a positive fact that this method does not need additional calculations and therefore it reduces significantly the time, which is required for 
selection of the optimised controller parameters by means of the proportional-integral-derivative (PID) controller. The PID controller compares the value of the required combustion timing with the value of the measured combustion time in the HCCI engine. There is generated in this way a control signal, which is necessary for reduction of a difference between the above-mentioned time values. Reduction of this difference is made possible by a position of the valve, which is determined for regulation of the intake air temperature. The physically-technical principle of the given procedure consists in analysis of the in-pressure values, whereby it is performed during measurement of the released heat.

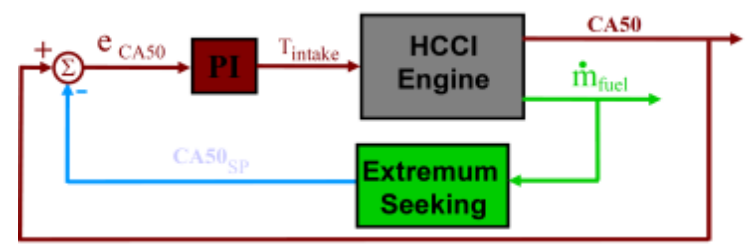

Fig. 3. Utilisation of the ES in the HCCI engine determined for minimisation of the fuel consumption

Application of the cost function in the ES enables to minimise the fuel consumption. The cost function is given by the average fuel consumption is relating to one hundred of the engine working cycles:

$$
J_{\text {fuel }}(\theta) \hat{=} \frac{1}{n_{f}-n_{0}}\left[\sum_{n=n_{0}}^{n_{f}} \dot{m}_{f u e l}(n, \theta)\right]
$$

where $n$ is the number of engine working cycles, $\dot{m}_{\text {fuel }}(n, \theta)$ is the value of fuel mass flow through the engine (in grams during 1 second) and $\theta$ is the correct value of combustion timing. It is possible to say with regard to the above-mentioned facts that the input parameter, which is determined for the cost function (as well as the parameter, which is adjusted by means of the ES), is defined as $50 \%$ of the set-point released heat value $\theta \hat{=} C A 50_{\text {setpoint }}$. The cost function is related to the engine fuel consumption in the interval $\left[\mathrm{n}_{0}, \mathrm{n}_{f}\right]$ after the delay of 200 engine working cycles. Therefore the ES is evaluated every 300 of the engine working cycles and the costs are calculated for the last 100 cycles.

The ES was applied in the case of a special HCCI engine, which is determined for the testing or experimental purposes and the utilized engine speed was determined at the level $1500 \mathrm{rpm}$ (Fig. 4).

Fig. 4 demonstrates an important fact that the ES decelerates the combustion timing up to the value $8 \mathrm{CAD}$ after TDC (ATDC) in comparison with the original combustion timing 3 CAD ATDC. Such modification of the combustion timing reduces the fuel consumption. The time interval of the optimisation process lasted 30 minutes, i.e. about 50 repeats along the horizontal axis in Fig. 4.

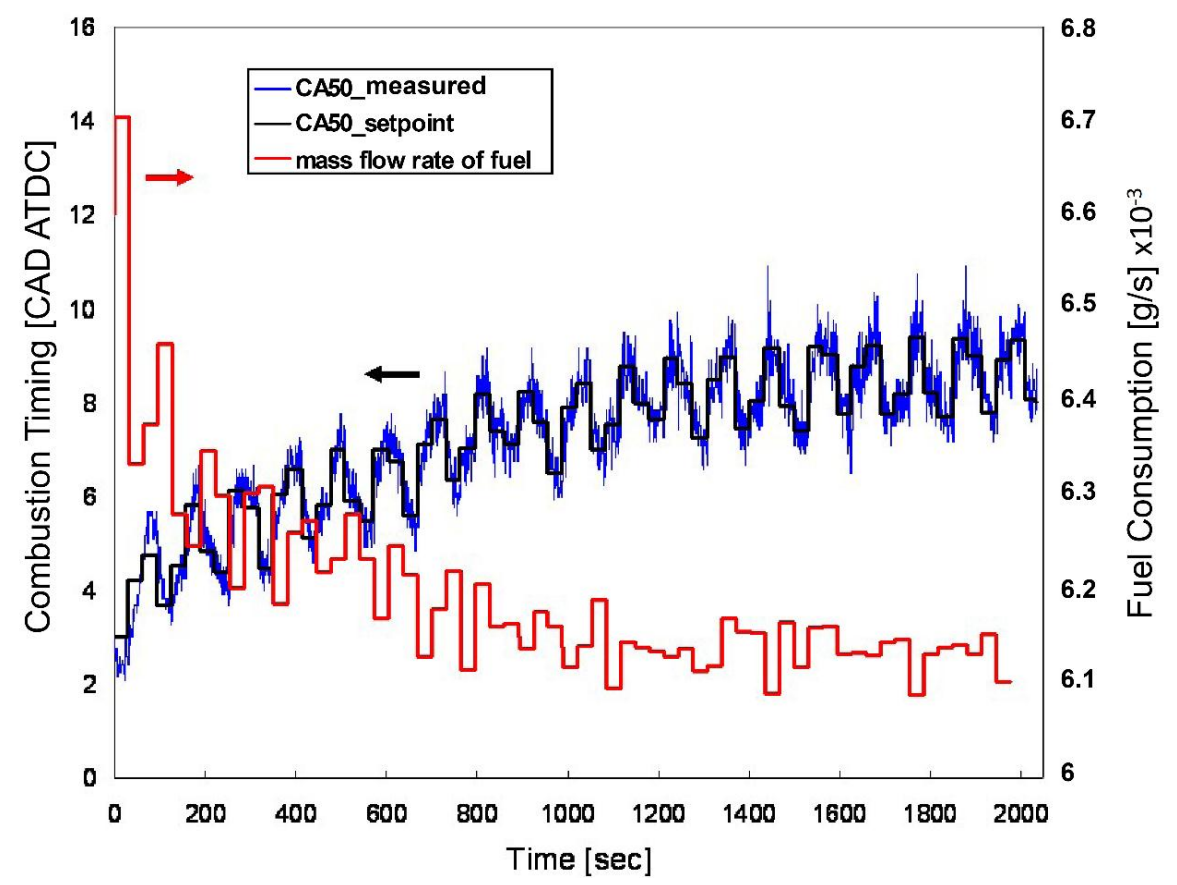

Fig. 4. Minimisation of the fuel consumption by the ES using modification of the combustion timing from 3 to 8 CAD ATDC with more conservative parameters 


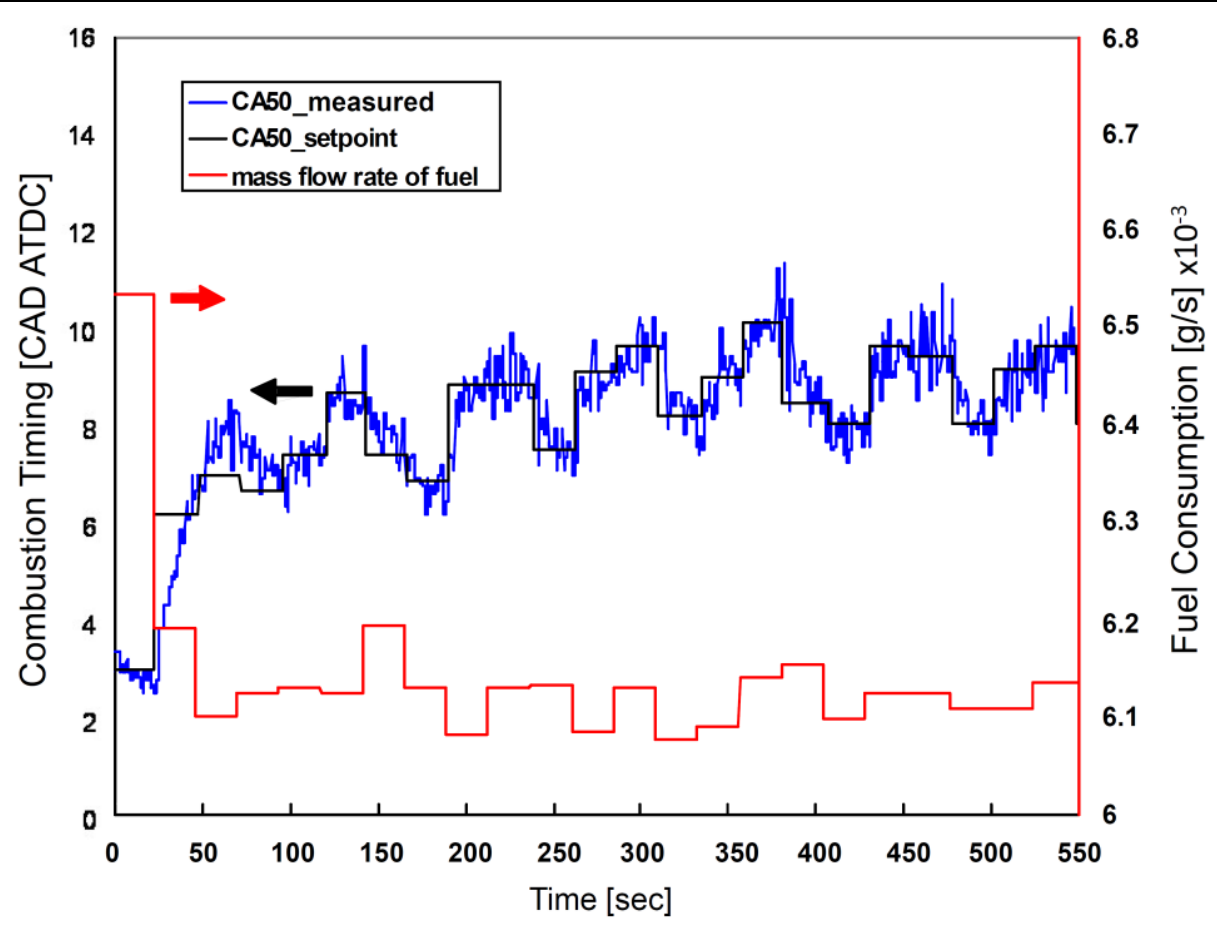

Fig. 5. Minimisation of the fuel consumption by the ES using modification of the combustion timing from 3 to 8 CAD ATDC with more aggressive parameters

The analogical experiment was performed using the same methodology, but with a higher value of the adaptation benefit. In this case the ES determined the same minimum level, however far more quickly (Fig. 5).

It is possible to say according to the obtained results as well as with regard to the performed analysis that the ES shifts the ignition time about 6 CAD later and thanks to this phenomenon it reduces the engine fuel consumption by more than $10 \%$.

These conclusions were practically tested in the case of a real vehicle, which was designed for the international competition shell eco marathon in London.

\section{CONCLUSIONS}

The research and development, which was performed, resulted in a significant reduction of the fuel consumption compared to the standard engine. Optimisation of the driving unit improved the combustion process in order to reach higher level of the fuel consumption efficiency with a positive influence on the environment due to reduction of the carbon oxide emissions. The results of our research work are presented periodically at the international competition Shell Eco-marathon in London. The system, which is based on thermal control of the HCCI technology developed for reduction of the vehicle $\mathrm{NO}_{\mathrm{X}}$ emissions in order to fulfil the future standard Euro 7, is applied in the experimental vehicle designed for participation at the international competition shell eco marathon 2018.

\section{SOURCE OF FUNDING}

This work was supported by the Slovak Research and Development Agency under the contract No. APVV-16-0259.

The article was written in the framework of Grant Projects: APVV-16-0259 "Research and development of combustion technology based on controlled homogenous charge compression ignition in order to reduce nitrogen oxide emissions of motor vehicles", VEGA 1/0473/17 "Research and development of technology for homogeneous charge self-ignition using compression in order to increase engine efficiency and to reduce vehicle emissions" and KEGA 041TUKE-4/2017 "Implementation of new technologies specified for solution of questions concerning emissions of vehicles and transformation of them into the educational process in order to improve quality of education."

\section{REFERENCES}

1. Wackerly D, Mendenhall W, Scheaffer R. Mathematical Statistics with Applications. Seventh Edition, Belmont, USA. 913. 2008.

2. Puškár M. Measuring method for feedback provision during development of fuel map in hexadecimal format for high-speed racing engines. Measurement. 2014;50 (1):203-212.

https://doi.org/10.1016/j.measurement.2014.01.005

3. Puškár M, Bigoš $P$. Method for accurate measurements of detonations in motorbike high speed racing engine. Measurement. 2012;45(3):529-534. https://doi.org/10.1016/j.measurement.2011.10.014 
4. Puškár $\mathrm{M}$, Bigoš $\mathrm{P}$, Puškárová $\mathrm{P}$. Accurate measurements of output characteristics and detonations of motorbike high-speed racing engine and their optimization at actual atmospheric conditions and combusted mixture composition. Measurement. 2012;45(5):1067-1076. https://doi.org/10.1016/j.measurement.2012.01.036

5. Puškár M, Bigoš $P$. Measuring of acoustic wave influences generated at various configurations of racing engine inlet and exhaust system on brake mean effective pressure. Measurement. 2013;46(9):33893400 .

https://doi.org/10.1016/j.measurement.2013.05.008

6. Czech P. Application of probabilistic neural network and vibration signals for gasket under diesel engine head damage. Scientific Journal of Silesian University of Technology. Series Transport. 2013; 78:39-45

7. Toman R, Polóni M, Chríbik A. Preliminary study on combustion and overall parameters of syngas fuel mixtures for spark ignition combustion engine. Acta Polytechnica. 2017;57(1):38-48. http://dx.doi.org/10.14311/AP.2017.57.0038

8. Chríbik A, Polóni M, Lach J, Ragan B. The effect of adding hydrogen on the performance and the cyclic variability of a spark ignition engine powered by natural gas. Acta Polytechnica. 2014;54(1):10-14. http://dx.doi.org/10.14311/AP.2014.54.0010

9. Bielawski PJ. Measurement and evaluation of mechanical vibration of reciprocating machines. Diagnostyka. 2012;1(61):25-30.

10. Czech P. Diagnosis of industrial gearboxes condition by vibration and time-frequency, scale-frequency, frequency-frequency analysis. Metalurgija. 2012; 51(4): 521-524.

11. Magdolen L, Masaryk M. Flywheel storage energy. Conference proceedings. Budapest University of Technology and Economy. 2012.

12. Komorska I. Modeling of vibration signal for reciprocating engine diagnostics. Diagnostyka. 2009;2(50);23-26.

13. Blist'an P. Blist'anová M. Molokác M. Hvizdák L. Renewable energy sources and risk management. International Multidisciplinary Scientific GeoConference: SGEM: Surveying Geology \& mining Ecology Management. 2012;4: 587-594.

14. Czech P. Identification of leakages in the inlet system of an internal combustion engine with the use of Wigner-Ville transform and RBF neural networks. 12th International Conference on Transport Systems Telematics Location: 2012;329: 414-422.

15. Kopilčáková L, Pauliková A. Technický metabolizmus $\mathrm{v}$ rámci orientovaného konštruovania. Manažérstvo životného prostredia. 8. konferencia so zahraničnou účast'ou (recenzovaný zborník referátov). Bojnice. 2008:55-57.

16. Puškár M, Brestovič T, Jasminská N. Numerical simulation and experimental analysis of acoustic wave influences on brake mean effective pressure in thrust-ejector inlet pipe of combustion engine. International Journal of Vehicle Design. 2015;67(1): 63-76. http://dx.doi.org/10.1504/IJVD.2015.066479.

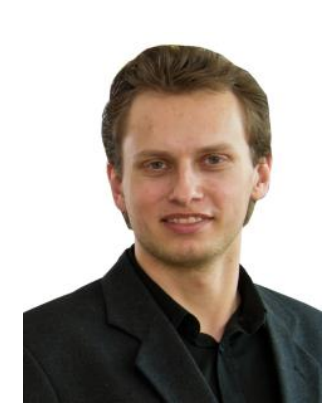

doc. Ing. Michal Puškár, PhD, is an Associate Professor in the Department of Engineering for Machine Design, Automotive and Transport at the Faculty of Mechanical Engineering, Technical University of Košice. His current fields of research interest are singletrack transport means, piston combustion engines and increasing their power output and reliability.

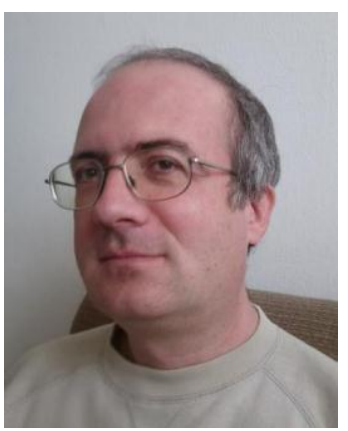

Ing. Melichar Kopas, $\mathrm{PhD}$, is a Lecturer in the Department of Engineering for Machine Design, Automotive and Transport at the Technical University of Košice. His professional orientation is focused on theory and design of transport machines and driving systems.

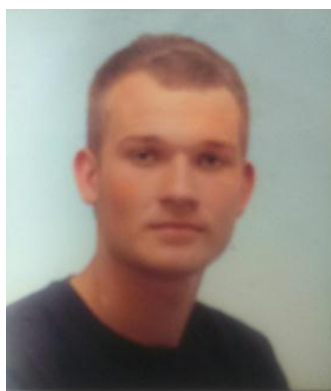

Ing. Dušan PUŠKÁR is graduate at the Faculty of Mechanical Engineering of the Technical University in Košice. $\mathrm{He}$ was a $\mathrm{PhD}$. student and member of shell eco prototype team on the Department of construction, Automotive and Transport Engineering. 